\title{
Perspectiva sobre la sequía actual
} 02 de mayo de 2021

\section{en México}
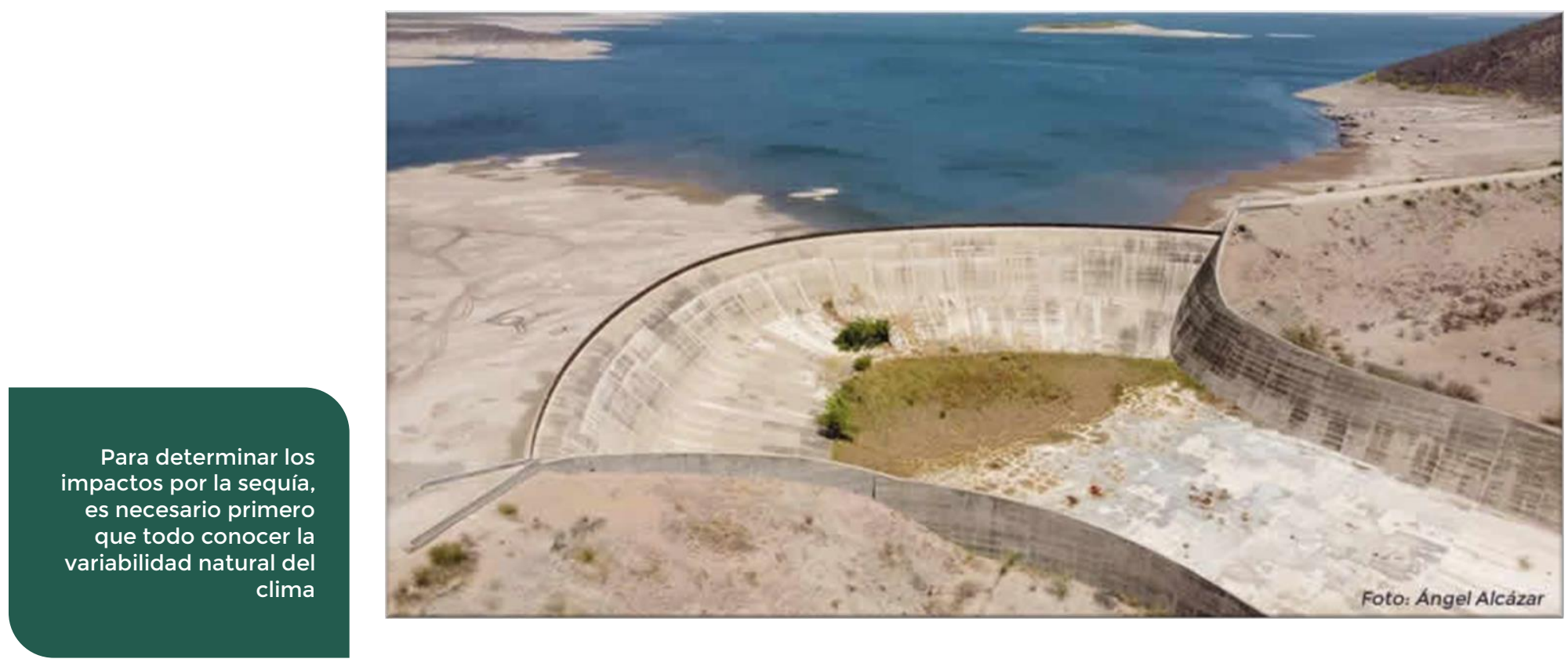

La sequía es un fenómeno natural que forma parte de la variabilidad del clima.

Las condiciones de sequía en México son recurrentes, aunque irregulares, y están normalmente regidas por la fluctuación de patrones climáticos, como variaciones en la actividad solar, o por la influencia tanto de fenómenos globales como de patrones atmosféricos de gran escala que son influenciados por variaciones de temperatura oceánica de baja frecuencia, como El Niño o La Niña.

Actualmente se presentan condiciones de sequía importantes en el país, probablemente las más severas desde los últimos diez años. El escenario actual corresponde a los escenarios climáticos derivados de La Niña, y está influenciado, sobre todo, en el norte del país, por el déficit de precipitación de 2020 , del cual no se ha visto una completa recuperación. Finalmente, dado que las sequías -a diferencia de otras amenazas- no tienen epicentro o trayectoria, sino una progresión lenta, es difícil determinar su inicio y, por ende, su término. Sin embargo, el mes de abril es parte de la temporada de estiaje, durante la cual se ven condiciones de precipitación reducida. 
Para superar estas dificultades, el monitoreo y diagnóstico de la sequía se realiza con ayuda de índices cuantitativos, que describen el comportamiento e interacción de variables meteorológicas e hidrológicas con condiciones de vegetación y humedad del suelo. Estos parámetros sirven como información de referencia sobre las anomalías climáticas, tanto para el público en general como para la investigación científica, y sobre la intensidad y el alcance espacial de las sequías.

Determinar la severidad de un evento de sequía no depende únicamente de la interpretación de índices, se requiere de la participación transectorial activa para conocer el comportamiento de este fenómeno climático a mayor profundidad. Esto llevará a una identificación oportuna de las sequías y, por tanto, a una mejor administración del recurso hídrico.

México cuenta con normativa y regulaciones para una mejor gestión del riesgo por sequías. Por un lado, están los programas de medidas preventivas y de mitigación a la sequía para cada uno de los consejos de cuenca (https://www.gob.mx/conagua/acciones-y-programas/programas-de-medidaspreventivas-y-de-mitigacion-a-la-sequia-pmpms-por-consejo-de-cuenca), los cuales forman parte del Programa Nacional Contra la Sequía (Pronacose) instaurado en 2013, y establecen metodologías de aplicación local en los 13 organismos de cuenca para la ejecución de planes de preparación y respuesta a las sequías. Su aplicación tiene por objetivo establecer las líneas de acción ante situaciones severas de escasez de agua para minimizar sus impactos sobre la calidad de vida de la población, el régimen de caudal ecológico y las actividades económicas.

Para determinar los impactos por la sequía es necesario primero que todo conocer la variabilidad natural del clima, así como su evolución, para que, con la ayuda de modelos climáticos y la observación directa o indirecta, sea posible conocer la evolución de la lluvia, temperatura en superficie, humedad del suelo, condición de la vegetación y su respuesta dinámica, entre otros factores.

Uno de los principales forzantes del clima en México y en el mundo es la dinámica de los océanos. Particularmente, la temperatura superficial del mar en el Pacífico ecuatorial determina la circulación atmosférica que interacciona con la zona continental e impacta en su régimen de precipitación A este fenómeno se le denomina El Niño, y sus efectos no solo alcanzan al continente americano, sino que impactan en prácticamente todo el planeta. Así, en combinación con otros tipos de oscilaciones (PDO, AMO, MJO, etc.), exacerban los impactos de la lluvia (déficit o exceso).

Información reciente del Centro de Pronóstico Climático de la NOAA describe la evolución de El Niño en su fase negativa, esto es, que a la fecha nos encontramos en una fase fría, condición de La Niña, con una tendencia hacia el calentamiento para alcanzar una condición neutra a partir del mes de junio, este patrón de circulación es típico de una condición de La Niña. Esta se ha mantenido desde el último trimestre del año 2020, y sus efectos son típicos de este comportamiento. Cuando se tienen condiciones de La Niña en invierno y primavera, se presenta regularmente una sequía en el centro y norte de México, lo que ha venido ocurriendo, y esta condición se ha visto amplificada en función de que la temporada de lluvia en esta región, sobre todo en el norte, estuvo por debajo de su valor promedio. Este patrón es similar al ocurrido en el año 2011, cuando una condición de La Niña en este periodo provocó que cerca del $80 \%$ del territorio nacional estuviera bajo alguna condición de sequía, ocasionando grandes pérdidas, principalmente a los sectores agrícola y ganadero.

Regularmente, excepto en el norte y vertiente del golfo de México, las precipitaciones se reducen de manera natural. A este período se le denomina de estiaje, y los recursos hídricos tienen una gran demanda derivada de las altas temperaturas prevalecientes al inicio de la planeación del riego para el 
sector agrícola y altas demandas para abastecer al público urbano, sin descuidar a la parte industrial y la conservación natural de los ecosistemas.

Durante el periodo primavera-verano es cuando se da el inicio de la temporada de lluvias en México de manera "escalonada", es decir, que el temporal de lluvias inicia en el sur y evoluciona hacia el norte. Un fenómeno en particular ocurre en el noroeste, llamado el Monzón de América del Norte, donde el régimen de precipitación está muy marcado, el cual inicia en julio y termina en septiembre. Durante este periodo ocurre aproximadamente el $75 \%$ del total de las precipitaciones, lo cual es importante, pues de otra manera no se alcanzaría el volumen adecuado para contar con la disponibilidad necesaria para todos los sectores antes mencionados, sobre todo el agrícola, porque esta es una de las regiones agrícolas más productivas del país.

En resumen, tenemos condiciones de sequía del centro al norte del país, principalmente, debido a que desde el año pasado se ha tenido un déficit que se vio exacerbado por las bajas precipitaciones durante el invierno de este año, considerando también que las temperaturas observadas han sido mayores al promedio, lo que ha requerido de una mayor demanda del recurso hídrico.

Para este año, hasta el mes de junio se esperan condiciones favorables para el centro-sur del territorio, mientras que continuará un déficit en el norte. Algunos modelos climáticos describen una canícula intensa, por lo que es posible que las condiciones de sequía prevalezcan, reestableciéndose el régimen de las precipitaciones durante el resto del verano y otoño. Un aspecto importante a considerar es que las proyecciones climáticas estacionales describen que será la vertiente del golfo de México, sur y sureste, donde las precipitaciones se verán reducidas.

Por otra parte, las proyecciones de la evolución de El Niño describen un periodo corto de condiciones neutras, describiendo que para el próximo invierno se vuelva a reestablecer una condición de La Niña. Aunque esta proyección en el contexto climático es de largo plazo, es necesario vigilar su evolución, en el sentido de que un régimen de lluvia bajo con una condición de La Niña nuevamente, traería un fuerte impacto al sector productivo y natural. Es necesario realizar planes de gestión de manejo de riesgos o bien retomar los que ya existen, como el Pronacose. 